SYMPOSIUM ON EVIDENCE BASED MEDICINE

\title{
Coordinating the norms and values of medical research, medical practice and patient worlds - the ethics of evidence based medicine in orphaned fields of medicine
}

\author{
R Vos, D Willems, R Houtepen
}

J Med Ethics 2004;30:166-170. doi: 10.1136/jme.2003.007153

See end of article for authors' affiliations

Correspondence to:

$R$ Vos, Health Ethics and

Philosophy, Department of

Health Care Studies,

Faculty of Health Sciences,

University of Maastricht,

PO Box 616, 6200

Maastricht, The

Netherlands;

Rein.Vos@ZW.unimaas.nl

Received

21 November 2003

Accepted for publication

27 November 2003
Evidence based medicine is rightly at the core of current medicine. If patients and society put trust in medical professional competency, and on the basis of that competency delegate all kinds of responsibilities to the medical profession, medical professionals had better make sure their competency is state of the art medical science. What goes for the ethics of clinical trials goes for the ethics of medicine as a whole: anything that is scientifically doubtful is, other things being equal, ethically unacceptable. This particularly applies to so called orphaned fields of medicine, those areas where medical research is weak and diverse, where financial incentives are lacking, and where the evidence regarding the aetiology and treatment of disease is much less clear than in laboratory and hospital based medicine. Examples of such orphaned fields are physiotherapy, psychotherapy, medical psychology, and occupational health, which investigate complex syndromes such as RSI, whiplash, chronic low back pain, and chronic fatigue syndrome.

It appears that the primary ethical problem in this context is the lack of attention to the orphaned fields. Although we agree that this issue deserves more attention as a matter of potential injustice, we want to argue that, in order to do justice to the interplay of heterogeneous factors that is so typical of the orphaned fields, other ethical models than justice are required. We propose the coordination model as a window through which to view the important ethical issues which relate to the communication and interaction of scientists, health care workers, and patients.
$\mathrm{E}$ vidence based medicine (EBM) is rightly at the core of current medicine. This holds not only from a scientific or clinical point of view, but also from an ethical point of view: if patients and society put trust in medical professional competency and delegate all kinds of responsibilities to the medical profession on behalf of that competency, medical professionals had better make sure their competency expresses the state of the art of medical science. What goes for the ethics of clinical trials also goes, broadly speaking, for the ethics of medicine as a whole: anything that is scientifically doubtful is, other things being equal, ethically unacceptable. This particularly applies to so called orphaned fields of medicine, that is areas of medicine where medical research is weak and diverse, is lacking financial incentives, and where the evidence regarding the aetiology and treatment of disease is much less clear than in laboratory and hospital based medicine. Examples of such orphaned fields are physiotherapy, psychotherapy, medical psychology, and occupational health. In these fields, complex syndromes such as repetitive strain injury syndrome (RSI), whiplash, chronic low back pain, and chronic fatigue syndrome (CFS) are investigated. There is an urgent need for well designed effect studies, preferably randomised clinical trials (RCTs), to distinguish effective from ineffective therapies.

It appears that the primary ethical problem in this context is the lack of attention to the orphaned fields. The problem may be diagnosed as a lack of evidence as such or as a lack of evidence that is appropriate to these specific fields and patients. Especially when allocation decisions are linked to the availability of evidence, matters of justice are at stake. This is potentially more so, because the seriousness or even the reality of some of the problems in these fields is doubted by many. ${ }^{1}$ Because of their complexity, their suspect reputation, and the need for multiple coordinated interventions, health problems at the intersection of body, mind, and society may not get the research and therapeutic effort they deserve. Although we agree that this issue deserves more attention as a matter of potential injustice, we want to argue that this specific form of complexity also calls for other models of analysis and evaluation. Our contention will be that, in order to do justice to the interplay of heterogeneous factors that is so typical of the orphaned fields we discuss, other ethical models than justice are required.

First, we will analyse the standard way of reasoning why orphaned fields in medicine are such difficult areas into which to extend the EBM methodology and the ethical problems related to it. This way of reasoning will be called the "intrusion model" of EBM, that is to say: EBM should intrude into medical fields which at present still lack an EBM practice. We will qualify this analysis by using some arguments from studies on therapies for chronic whiplash, chronic pain, chronic fatigue, and the repetitive strain injury syndrome. Secondly, we will propose another ethical way of reasoning about this problem, claiming that guidelines and instructions following from EBM have to coordinate different normative logics: the logic of clinical trials and other scientific methodologies, the logic of medical practice, and the logic of patient worlds, each normative logic being beset by a set of normative issues. This will be called the "coordination model" of EBM. That is to say: diagnostic, therapeutic, and other health care procedures have to coordinate different worlds of norms and values, those of scientists, doctors, and other health care workers, and also those of patients. Thirdly, we will introduce the political philosophy of Laurent Thévenot and Luc Boltanski, who have 
developed a theory, as a way of dealing with different worlds of norms, of the origin of social conflicts and the resolution thereof as a clash of the coordination of different contexts of justification. Thus, it can be shown that the analysed models are not contrary, but complementary models of EBM, and that they represent two complementary strategies of dealing with normative problems related to EBM. Correspondingly, ethics of justice and autonomy ought to be combined with pragmatist ethics of deliberation.

\section{THE STANDARD WAY OF REASONING ABOUT EVIDENCE AND ETHICS IN ORPHANED FIELDS: THE INTRUSION MODEL}

Discussions about orphaned fields such as physiotherapy, medical psychology, occupational health, and nursing are very often framed by the notion that such fields lack an evidence based practice but that attempts should be made to improve such practices. In many cases this does indeed seem to be the case. The Dutch Health Council stated in its 1999 report, The Effectiveness of Physical Therapy, based on a systematic review covering 169 RCTs, that in contrast to their widespread use in Dutch health care, there was little or no evidence of the effectiveness of electrotherapy, laser therapy, and ultrasound therapy. ${ }^{2}$ The health council advised the professional organisation of physiotherapists to revise their guidelines on the use of physiotherapy in the treatment of musculoskeletal disorders. Many other forms of physiotherapy can be shown to be effective-for example, exercise therapy as an additional treatment to medication in Parkinson's disease. ${ }^{3}$ Another example is cognitive behaviour therapy (CBT) which has been proven effective in randomised trials as a treatment of CFS, whereas somatic and pharmacological treatments have not been proven effective. These results, however, are largely neglected by medical professional groups. ${ }^{45}$ These examples show that orphaned fields of medicine are not resistant to EBM methodology as such.

Yet, in many cases the problem is much more difficult: two types of problem illustrate this. The first occurs when medical and psychological approaches conflict, the second when medically inexplicable disorders are involved. The case of chronic neck pain due to whiplash is illustrative of the first type of problem. Chronic neck pain in case of whiplash is frequently associated with psychological distress. Wallis et al questioned whether these affective disturbances are the cause or the effect of chronic neck pain. ${ }^{6}$ They designed a clinical trial to test this hypothesis. If a medical intervention-that is, radiofrequency neurotomy-lessened the psychological distress, this would be evidence for the medical model, meaning that the affective disturbances are epiphenomena of the organic disorder. If improvement did not occur, then the psychological model would hold, in the sense that psychological factors could sustain pain complaints, even if the organic disorder had been "cured". Wallis et al found that psychological distress decreased, not only in a group of patients with chronic neck pain but also in a subgroup of patients with fewer complaints of neck pain. Thus, they confirmed the medical model. This finding evoked fierce debate, initiated through a letter to the editor in the renowned journal Pain by Kendall et al. ${ }^{7}$ These authors referred to the biopsychosocial model, claiming that many feedback loops between medical, psychological, and social factors occur. Evidence based medicine would have it that science should resolve this conflict and should collect the necessary evidence to decide which model is correct, since evidence based decisions have important consequences for the diagnosis and treatment of whiplash. The ensuing discussion shows, however, that this may not be very promising when theoretical models which cross the boundaries between different disciplines are at stake. Rather than a Popperian cycle of trial and error, such disputes are reminiscent of Kuhn's reflections on the incommensurability of paradigms.

The second type of problem is exemplified by the case of RSI which has evolved in a short period of time as a generally recognised serious condition. ${ }^{8}$ In many countries it is considered as one of the important occupational risks for workers and employees in the administrative and business sector, potentially even the most important occupational risk. Many programmes and preventive measures are being developed and applied. Medical science has not, however, found a decisive causal scheme of explanation for the syndrome. The number of categories of patients at risk for RSI is still expanding, but experts doubt or at least question the value of RSI checklists. Most medical treatments and preventive strategies for RSI have not yet been scientifically proven, and even the definition and categorisation of RSI differs between countries. ${ }^{9}$ In such cases it is very difficult to decide on what the evidence should be. Even on the very concept of RSI there is as yet no international consensus. Epidemiological classifications are different in different countries and figures on incidence and prevalence of RSIlike complaints may vary enormously. In different countries within the Western world, people with similar complaints might end up with profoundly different diagnoses and treatment trajectories, including: preventive measures of all kinds and sorts; treatment by neurologists, orthopaedic surgeons, pain specialists, or physicians in rehabilitation medicine; various kinds of physical therapy; stress psychology techniques; and other psychotherapeutic approaches.

Indeed, both types of problems are complex cases, typical of orphaned fields in medicine, and they show how difficult it is to expand the EBM methodology into orphaned fields of medicine. In these fields it is much more difficult to define and collect the right evidence because of: the long period of time of the disease course; the poor or nonavailability of control groups; the interplay of different interventions at the same time; and many other factors which show how complex it is to apply EBM methodology in these areas. The attempts to expand the EBM methodology into the daily practice of professionals and patients are framed, however, in the same way as in standard areas of EBM: scientific evidence needs to be collected and to be translated into guidelines, protocols, instructions, and procedures, which then should "intrude" into the world of professionals and patients. The term "intrusion" is appropriate, since it conveys that criteria, norms, and values from the medical scientific world enter the worlds of professionals and patients, the consequences of which have to be revealed in terms of possible threats to autonomy and justice.

Based on the intrusion model, the role for ethics would be to assess the consequences of the spread of EBM principles and procedures, and to raise criticisms if such consequences pose potential threats to a just distribution of health care resources, to patient autonomy, and to other normal ethical focus points. Preferably, this should include the notion that implicit and unintended consequences should be made explicit. A number of different recognised ethical frameworks might be employed to perform such an ethical assessment: consequential, deontological, utilitarian, communitarian, etc. These ethical problems must be taken seriously and must be discussed. Our claim is that these ethical issues pose important problems for the further expansion of EBM methodology. Orphaned fields of medicine also, however, exhibit another set of ethical problems related to the expansion of EBM methodology. 


\section{THE ALTERNATIVE WAY OF REASONING ABOUT EVIDENCE AND ETHICS IN ORPHANED FIELDS: THE COORDINATION MODEL \\ The challenge of collaboration and coordination}

The assumption of EBM medicine is that scientific medical knowledge is primarily associated with established outcomes from patient related research, and that guidelines are the best vehicle for introducing these scientific insights into medical practice. Undoubtedly, scientific evidence and guidelines are useful, but they are merely instrumental for the delivery of high quality patient care. The practice of orphaned fields in medicine as discussed above shows, however, another assumption: the one to one relationship of the medical scientist versus the clinician (or general practitioner) does not fit the complex structure of orphaned fields in medicine. Here, different groups of professionals have to collaborate and different perspectives have to be adapted. The literature on RSI, chronic pain, and chronic fatigue shows the importance of optimal collaboration and communication between different professional groups, such as physicians, psychologists, psychotherapists, and physiotherapists. Further, it is shown that patient participation has important effects on health outcome. Baker et al examined whether physical therapists sought to involve patients in therapeutic goal setting and, if so, what methods they used. ${ }^{10}$ The therapists stated that they believed it was important to include patients in goal setting activities and that outcomes would be improved if patients participated. Further, patients indicated that participation was important to them. Another example of the important effects patient participation can have on health outcome is provided by a recent programme in the Netherlands, which included patients' organisations in the assessment and evaluation of research proposals, one of which focused on the evaluation of a rehabilitation therapy programme in the patients' own neighbourhood. ${ }^{11}$

These insights regarding professional collaboration and patient participation parallel the growing awareness in the EBM literature that EBM has a far wider meaning than it was thought to have in the early 1980s, when it first came into use. The Dutch Health Council reports that EBM "is currently understood to incorporate clinical epidemiological data, meaningful deliberations of professionals such as pathophysiological knowledge, and clinical experience, together with patient preferences" (Health Council, ${ }^{2}$ p 13).

If one focuses on optimum patient care, then one has to distinguish between the scientific aspect, professional knowledge and competence, and social developments. This is important, particularly as health care practices become increasingly interconnected and have to deal with patients' increased understanding of medical issues and their desire to be involved in determining what constitutes good health care. As the Dutch Health Council notes:

\section{Generally speaking, professional knowledge and compe- tence are characterised by the skilful application of scientific knowledge to concrete situations or put another way: being able to translate from the generic to the specific. In the case of medical professionals this transla- tion process effectively boils down to integrating epide- miological information (whether or not it is incorporated in guidelines), patient specific data (including expressed preferences) and a host of organisational preconditions (Health Council, ${ }^{2}$ p 14).}

Thus, the council speaks of the "learning professional" and states that it is vital "that 'learning professionals' also systematically establish and evaluate their own practice data, so as to build up a reservoir of practical knowledge which complements the external knowledge from patient related epidemiological research" (Health Council, ${ }^{2}$ p 14). Therefore, we have to think about professionals as individuals with competence and governance, yet also as members of organisational networks. The literature on "continuing professional education" reflects this new way of thinking: not only scientific education and training are important, but also education in management, cooperation, and social skills. ${ }^{2}$ This shows that norms and values from medical science, clinical practice, and patients have to be interconnected, which we think it is useful to denote as the coordination model of EBM. Apart from norms and values, different forms and sources of evidence must also be communicated.

\section{Biographical documents as a source of evidence}

From an epistemic point of view, orphaned fields in medicine show that evidence comes from different sources, runs through different contexts, and meets different perspectives. From an ethical point of view, a different set of ethical issues emerges related to how patients' experiences and values can be met. This demand to accommodate the perspectives, norms, and values of patients and patient groups surpasses the discussion on the integration of patient perspectives, patient satisfaction, and quality of life considerations in medical research. Orphaned fields in medicine offer evidence of this from an important source: biographical or so called ego documents. These biographical documents are generally written by patients suffering from chronic diseases, both curable and incurable, explained or unexplained. ${ }^{12-14}$ Nowadays the internet offers an abundance of biographical documents. In general, these documents can function as a window on the lives of patients. It is of particular interest that the medical perspective is usually only one among several, and we can see patients struggle with the problem of how to integrate medical information and advice into their self images, prospects, and plans. For people with a relatively long history of several diagnoses, treatment plans, surgery and recovery periods, and encounters with many health care professionals, medical information and options will enter into a cluster of experiences and perspectives entirely different from patients with acute or singular complaints. From ego documents we can learn that, especially in the field of unexplained or controversial diseases such as chronic pain and fatigue syndromes, many patients clamour for recognition of their status as experts from experience.

\section{THE COORDINATION OF DIFFERENT WORLDS OF NORMS}

How should we consider the two analysed models of EBM in orphaned fields of medicine? What is their relationship? What kinds of strategies are available for medical ethics to deal with these? The political philosophy developed by Thévenot and Boltanski might help us to clarify the analysed models of EBM in orphaned fields in medicine. ${ }^{15}$

Laurent Thévenot and Luc Boltanski developed in their Les Economies de la Grandeur a political theory which analyses societal conflicts as the clash of two or more different contexts of justification. They claim that all sorts of "technical objects" may help to enable compromises in such conflicts-that is, they say that these objects are able to coordinate such normative conflicts. ${ }^{15}$ The object of their central case study is the buggy. Buggies have been designed to enable the transport of small children much more efficiently than was possible with the classical baby carriage. Buggies are foldable and thus easily transportable by train, car, and airplane. The disadvantage, however, is the potential 
danger for the baby if a buggy should fail to unfold completely. Safety and transportability, two norms from completely different worlds-one of child care and one of consumer comfort-have to be coordinated. The finalised buggy accomplishes this task through a "click" which demonstrates that the buggy is fixed. Such a click is a frequently used and socially acceptable way to show that the coast is clear, as in the case of safety belts in cars and airplanes. The click shows that one normative world-safety for the child-is ensured and that another normative world can be initiated-transport of the child.

The philosophy of Thévenot and Boltanski has been applied to the field of science and technology studies in order to better understand why and how medical technologies which have usually been regarded as being in the domain of the work and responsibilities of physicians can be transferred to their patients. ${ }^{16}$ In many cases of medical therapy, patients are being involved and made responsible for their own treatment. In the case of asthma-for example-patients use the peak flow instrument to measure their breathing capacity, note the results of these measurements in diaries, and perform all kinds of diagnostic and therapeutic measures, most of what they do being described under the heading of self-management. In such cases medical scientific views may conflict with the perspectives of patients. One of Willems's interviews-for example-explores the case of a 14 year old boy suffering from asthma, who was active as a player in his school basketball team:

What I find so troublesome is not that I become breathless during the game; mostly this I can handle, I hang back in the field, I do not run continuously back and forth, and this will do. I am much more troubled by the wheezing after the game. In the dressing room I see my fellow players look at me, then I have no wish to take out my spray apparatus; yes, I feel ashamed of doing so. ${ }^{16}$

In this particular case the spray apparatus does not succeed in adapting the norms of good asthma care with the norms of normal behaviour of the friends of the 14 year old boy. Now, however, the new turbuhaler, which is less tedious and much faster in spraying the anti-asthmatic drug, has been developed. By pulling the turbuhaler and "clicking" the apparatus, the boy would immediately be able to inhale the drug without being noticed by his fellow players. In line with the reasoning of Thévenot and Boltanski, it can be concluded that there are two ways of looking at the effectiveness of asthma technologies: one which looks at the consequences or the effects of a particular technology (which intrudes into the life worlds of physicians and patients), and the other which looks at how norms of science, practice, and patients are connected (which are compromised and which are complementary).

Our claim is that this is a very elegant model for discussing the ethical problems related to EBM and for interpreting the two sets of ethical problems related to orphaned fields in medicine analysed above. What is shown for technical artefacts, that is for apparatus, can be extended to all kinds of technologies including the "soft" technologies of EBMthat is, evidence based guidelines, protocols, instructions, and procedures. The important point here is that these two ways of evoking and dealing with ethical problems are complementary rather than antagonistic. The turbuhaler might be successful in terms of coordinating specific norms of physicians and asthma patients, yet it might still have (unintended) consequences for physicians and patients in other respects which have to be dealt with, explicated, and valued (in terms of potential threats to autonomy and justice). In the same way evidence based guidelines and protocols might be successful in coordinating the different logics of science, practice, and patient worlds, yet might have (unintended) consequences in terms of autonomy or justice. Both models of EBM and related ethical problems have to be considered and evaluated.

\section{CONCLUDING REMARKS}

Although we sympathise with pleas for recognition of the fact that the same scientific standard need not and cannot apply in all branches of medicine, we do not want to pursue this particular ethical line of argument, in terms of utility or justice, concerning "weak" and "peripheral" disciplines and fields. This partly has to do with the politics of knowledge. Rather than defending areas of medicine against EBM, it might be wise to invest in reforming and expanding the EBM movement. Evidence based medicine is about the best available evidence and this does not rule out methodologies other than the RCT. ${ }^{17}$ A priori arguments about the complex and idiosyncratic nature of certain fields are doubtful in general, and they may hide conservative "art versus science" types of attitudes. ${ }^{18}$ In particular, we want to criticise the idea that orphaned fields of medicine are marginal and weak and that by the implementation of EBM these areas will become full members of the medical community. The examples described in this paper show that orphaned fields of medicine have an intriguing way of making use of evidence, which also provides a deeper understanding of the standard areas of hospital based medicine: orphaned fields are arenas where different professionals have to deal with evidence in the context of the diagnosis and treatment of complex problems and complex patients. These orphaned fields exhibit the pattern of dealing with evidence in the context of cooperation and delegation of responsibilities between physicians and other health care workers. This is by itself relevant, but the more so because it reflects the increasingly important practice in medicine of integrated care for complex, chronically diseased, and ill people. However orphaned these fields may appear to be, they are, and should be, central to the medical understanding of patient care and the ethical analysis of it.

This is why we think it is important not to reject EBM a priori as altogether irrelevant to orphaned fields, but instead to present a different model for including EBM in these fields: the coordination model. This model opens a window to important ethical issues which relate to the communication and interaction between scientists, health care workers, and patients. In long term and complex disease and illness trajectories, the role of the professional is not limited to confronting the patient with the best evidence at a specific time in a specific condition and with regard to specific options. Professionals have to discuss long term plans under conditions of uncertainty and in view of diverse knowledge sources, both from other professionals and from patients. Also, the ethical issue is not limited to whether the patient is given proper information and sufficient choice and to whether the patient's autonomy is respected at discrete moments regarding singular decisions. In the orphaned fields, ethical issues typically have to do with broader matters of recognition, shared decision making, and a more symmetrical and deliberative relationship between professionals and patients, in which all parties are prepared to learn from all others. ${ }^{19}$ Hence, we need to organise health care practices in such a way that diversity does not result in mutual disregard but in continuous learning. ${ }^{18}$ Whether learning and deliberation stimulated by such an approach lead to defensible outcomes should continue to be measured by the yardstick of an ethics of justice and autonomy. 


\section{Authors' affiliations}

R Vos, R Houtepen, Health Ethics and Philosophy, Department of Health Care Studies, University of Maastricht, Maastricht, The Netherlands D Willems, Medical Ethics, Department of General Practice, Academic Medical Centre, University of Amsterdam, Amsterdam, The Netherlands

\section{REFERENCES}

1 Shorter E. A history of psychosomatic illness in the modern era. New York: Free Press, 1992.

2 Health Council. De effectiviteit van fysische therapie-electrotherapy, lasertherapie, ultrageluidbehandeling [The effectiveness of physical therapyelectrotherapy, laser therapy, ultrasound treatment]. The Hague: Health Council, Dutch Government Press, 1999.

3 De Goede CJ, Keus SH, Kwakkel G, et al. The effects of physical therapy in Parkinson's disease: a research synthesis. Arch Phys Med Rehabil 2001;82:509-15.

4 Whiting $\mathbf{P}$, Bagnall A, Sowden A, et al. Interventions for the treatment and management of chronic fatigue syndrome: a systematic review. JAMA $2001 ; 286: 1360-8$.

5 Prins JB, Bleijenberg G, Bazelmans E, et al. Cognitive behaviour therapy for chronic fatigue syndrome: a multicenter randomised controlled trial. Lancet 2001;357:841-7

6 Wallis BJ, Lord SM, Bogduk N. Resolution of psychological distress of whiplash patients following treatment by radiofrequency neurotomy: a randomised, double blind, placebo controlled trial. Pain 1997;73:15-22.

7 Kendall N, Main CJ, Linton SJ, et al. Reply to Wallis, et al [letter]. Pain 1998;78:223-5.
8 Health Council. RSI. The Hague: Health Council, Dutch Government Press, 2000.

9 Arksey H. RSI and the experts. The construction of medical knowledge. London: UCL Press, 1998.

10 Baker SM, Marshak HH, Rice GT, et al. Patient participation in physical therapy goal setting. Phys Ther 2001;81:1118-26.

11 Vink A. Patiënten als referenten van onderzoek [Patients as reviewers of research]. Mediator 2003;14:10-11.

12 Hawkins AH. Reconstructing illness: studies in pathography. West Lafayette: Purdue University Press, 1993.

13 Oderwald A. Lijden tussen de regels: overzichtsstudie naar egodocumenten van chronisch zieken [Suffering between the lines: a review of biographical documents of chronically ill patients]. Zoetermeer: Nationale Commissie Zieken, 1994.

14 Frank AW. The wounded storyteller: body, illness and ethics. Chicago: University of Chicago Press, 1995.

15 Thévenot L, Boltanski L. Les economies de la grandeur. Paris: Gallimard, 1991.

16 Willems D. Dokters and patiënten in kleine technologie [Physicians and patients in small technology]. In: Berg M, Mol A, eds. Ingebouwde normen-medische technieken doorgelicht [Built in norms-medical technologies being screened]. Utrecht: Van der Wees Uitgeverii, 2001:61-70

17 Ter Meulen RH, Dickenson DL. Into the hidden world behind evidence based medicine. Health Care Anal 2002;10:231-41.

18 Vos R, Houtepen R, Horstman K. Evidence based medicine and power shifts in health care systems. Health Care Anal 2002;10:319-28.

19 Widdershoven GA, Verheggen FW. Improving informed consent by implementing shared decision making in health care. IRB 1999;21:1-5. 